\title{
Missed Prevention of Mother-to-Child Transmission of HIV (PMTCT) Visits and Associated Programmatic Predictors: A Pilot Study
}

\author{
Augustine Ndaimani1 ${ }^{*}$, Inam Chitsike2, Clara Haruzivishe1, Babill Stray-Pedersen ${ }^{3}$ \\ ${ }^{1}$ Department of Nursing Science, University of Zimbabwe College of Health Sciences, Harare, Zimbabwe \\ ${ }^{2}$ Department of Paediatrics, University of Zimbabwe College of Health Sciences, Harare, Zimbabwe \\ ${ }^{3}$ Division of Women, Rikshospitalet, Institute of Clinical Medicine, University of Oslo, Oslo, Norway \\ Email: ^ndaimania@gmail.com
}

How to cite this paper: Ndaimani, A., Chitsike, I., Haruzivishe, C. and Stray-Pedersen, B. (2017) Missed Prevention of Mother-to-Child Transmission of HIV (PMTCT) Visits and Associated Programmatic Predictors: A Pilot Study. Advances in Infectious Diseases, 7, 107-117.

https://doi.org/10.4236/aid.2017.74011

Received: September 7, 2017

Accepted: October 30, 2017

Published: November 2, 2017

Copyright $\odot 2017$ by authors and Scientific Research Publishing Inc. This work is licensed under the Creative Commons Attribution International License (CC BY 4.0).

http://creativecommons.org/licenses/by/4.0/

c. (i) Open Access

\begin{abstract}
Missed Prevention of Mother-to-Child Transmission of HIV (PMTCT) visits have contributed to the delayed achievement of elimination of mother-to-child transmission of HIV. Missed visits promote attrition from prevention of mother-to-child transmission of HIV program and antiretroviral drug resistance. The purpose of the study was to determine the prevalence of missed PMTCT visits and its associated predictors. A descriptive cross sectional survey was carried out at a District Hospital in Goromonzi, Zimbabwe. Fifty-three women completed closed-ended questionnaires pertaining to PMTCT visits and exposure to PMTCT activities. A total of $24.5 \%$ missed at least one scheduled PMTCT visit. Statistically significant predictors of not missing a PMTCT visit were satisfaction with family support $(\beta=-0.73, p=0.029)$ and level of satisfaction with PMTCT services $(\beta=-0.00076 ; p=0.04)$. The number of days by which scheduled visits were missed were inversely correlated with visit number $(\beta=-2.99, p=0.04)$. Enhanced family support and quality improvement to improve patient satisfaction may reduce missed visits. Availing women with a more active role in PMTCT may also reduce the prevalence of missed visits.
\end{abstract}

\section{Keywords}

Missed Visits, Option B Plus, Pilot Study, PMTCT

(Prevention of Mother-to-Child Transmission of HIV), Predictors 


\section{Introduction}

Prevention of Mother-to-Child Transmission of HIV (PMTCT) is a key strategy in the global AIDS response towards elimination of HIV and AIDS by 2030 [1]. Since the launch of the elimination of mother-to-child transmission of HIV initiative (eMTCT) countries such as Cuba, Armenia, Belarus and Thailand have eliminated mother-to-child transmission of HIV (MTCT) [2] [3]. To achieve elimination breastfeeding, countries need to have MTCT rates $5 \%$ or below; non-breastfeeding populations need to sustain MTCT rates of $2 \%$ or below [4]. Africa, where the majority of countries are breastfeeding countries, has so far been unable to achieve and maintain an MTCT rate of 5\% and below. Zimbabwe has managed to reduce MTCT rate to 6.7\%, due to effective PMTCT program. However, the program is impeded by poor retention rates. A 2012 survey in Zimbabwe found an attrition rate of 43\%, along the PMTCT cascade [5]. Attrition in PMTCT is usually due to loss to follow up and death. Both of the two are associated with missed PMTCT appointments.

Countries are aiming to achieve the 90-90-90 targets by 2020. According to the targets, by the year $2020,90 \%$ of people with HIV should know their status and $90 \%$ of people diagnosed with HIV infection should be on lifelong antiretroviral therapy. The last 90 in the $90-90-90$ strategy aims to have $90 \%$ on ART having viral suppression [6]. Missed PMTCT and HIV care visits may stall progress towards elimination of HIV by increasing resistance to antiretroviral medicine and worsening clinical, virologic and immunonologic outcomes. It also increases treatment costs as individuals get managed on relatively expensive second line or third line ARV medicine [7] [8]. About 35\% of adults with HIV in Zimbabwe are reported to be on second line ARV drugs.

Many innovative strategies have been used to improve retention in PMTCT, hence reduce the frequency of missed visits. The retention interventions can be health centre based or community-based. In a 2016 systematic review of interventions to improve retention, identified strategies to improve retention in PMTCT included task-shifting to enable nurses to prescribe antiretroviral drugs, integrating PMTCT services in antenatal clinics (ANC), quality improvement at health centres, CD4 testing at health centres, facility-based peer support, encouraging male partner support and using cell phone reminders [9]. Incentives, reinforcement, mobile phone education, laboratory courier for CD4 samples and education of midwives were also proved to improve retention in PMTCT [10].

Despite all these interventions being implemented in most settings, retention remains poor [11]. There is also little documented evidence of missed visits and their correlates in public PMTCT programs, including predictors of missed visits in such settings. More so, the evidence is lacking since the world Health Organization recommended the PMTCT Option B plus and, recently, the test and treat strategy. The purpose of this study was to determine the prevalence of missed PMTCT visits and determine programmatic PMTCT predictors of missed visits. 


\section{Methodology}

The pilot study was conducted through a descriptive survey method in October 2016. Two questionnaires were administered. Both questionnaires had closed-ended items. They were administered to randomly selected women enrolled in PMTCT at Makumbe District Hospital, Zimbabwe. The study site was purposively selected for having a diverse catchment area, which included rural and urban population. Randomization was achieved through coin flipping. Only women enrolled in PMTCT Option B plus at the site and could understand either English or the vernacular Shona language were approached. Women who were enrolled in the Option B program or who visited the PMTCT centre for emergency supply of antiretroviral drugs [ARVs] were excluded from the study. A total of 53 women were selected to participate in the study. The sample size was based on the central limit theorem [12]. The study was then explained, including the concept of voluntary consent. Participants proceeded to complete the questionnaire after giving voluntary documented consent. Participant visit information was obtained from respective OI/ART (Opportunistic Infections antiretroviral therapy) registers. The main outcome measures were missed PMTCT visits and number of days by which scheduled visits were missed.

\section{Ethical Considerations}

The study observed ethical principles according to the Nuremberg code. The investigator had a valid competence in ICH-GCP (International Conference on Harmonization-Good Clinical Practice). Approval to conduct the study was granted by both the J REC (Joint Research Ethics Committee for University of Zimbabwe College of Health Sciences and Parirenyatwa Group Hospitals) and The Medical research Council of Zimbabwe (MRCZ). Data were analyzed for descriptive statistics and both multiple linear and multiple logistic regression using STATA software.

\section{Results}

\subsection{Demographic Features}

Fifty-three women in PMTCT participated in the study. The age of participants showed a multimodal beta distribution with modal ages of 29, 32 and 33 years $(\gamma=-0.003 ; \mathrm{SD}=6.7)$. Forty-one $(77.4 \%)$ participants had attained secondary school education; one [1.9\%] had a tertiary education qualification. Forty-six (86.8\%) participants were rural dwellers. Thirty (56.6\%) participants were unemployed. It was not surprising that $46(86.8 \%)$ had a monthly income not exceeding US\$250. On the other hand, 48 (90.6\%) were Christians while 2 [3.8\%] were affiliated to the traditional religion. Thirty participants $(56.6 \%, 95 \% \mathrm{CI}=0.4$; $0.7)$ were pregnant and $43.4 \%(95 \% \mathrm{CI}=0.3 ; 0.6)$ were breastfeeding. Both the duration of pregnancy and duration of breastfeeding were negatively skewed. The median duration of pregnancy was 6 months (IQR $=2$ months). The median duration of breastfeeding was 5 months (IQR $=9$ months). The male con- 
dom, used by 19 (35.8\%) and The Progesterone only pill (POP), used by 13 (24.5\%) participants and Depo Provera, used by 10 (18.8\%) participants, were the commonly used methods of family planning by the participants. All participants had disclosed their HIV positive status to their husbands or partners. The participants' demographic characteristics are summarized in Table 1.

\subsection{Current Visit Information}

Forty-seven (88.7\%) participants the health centre as their usual source of health care and $30(56.6 \%)$ had visited the health centre at least once in the previous year. Only seven (13.2\%) spent more than 3 hours coming to the health centre. The participants' mean distance from the Hospital was $8.1 \mathrm{~km}(\mathrm{SD}=5.4 \mathrm{~km})$ and travelled to the Hospital in an average of 57 minutes ( $\mathrm{SD}=38.3$ minutes). Thirteen [(4.5\%) participants had missed a scheduled visit. Another 13 (24.5\%) were members of an HIV-related support group. Since commencing the recent PMTCT program, the participants had a mean of $7(S D=5.4)$ PMTCT visits. On the other hand, the participants had a median of 12 months (IQR $=19$ months, skewedness $=2.7$ ). Lastly, the participants had missed the current scheduled visit by up to 62 days. Those who had come earlier than the scheduled review date did so by up to 23 days before the scheduled PMTCT visit. Those who reported having come to the PMTCT centre were 22 (41.5\%). The mean participants' CD4 count was 463 cells $/ \mu \mathrm{L}(\mathrm{SD}=322.6$ cells $/ \mu \mathrm{L})$. Participants $\mathrm{CD} 4$ counts ranged between 6 and 1360 cells $/ \mu \mathrm{L}$. Data for the current participant visit is summarized in Table 2.

\subsection{Participants' PMTCT Experience at the Site}

According to Table 3 which summarizes the participants' PMTCT experience, 39 (73.6\%) did not get peer support in PMTCT. Eighteen (34.0\%) received community health worker support. Motivation to come for PMTCT visits included cell phone reminders, for 15 (28.3\%) participants and cash motivation, for 5 (9.4\%). Nobody was referred to another health centre for ARV drugs. While $52(98.1 \%)$ were attended by a female nurse at the PMTCT centre, 27 (50.9\%) did not know the nurse by name. Few participants had paid for consultation, medical supplies, laboratory investigations and medication. However, 46 (86.8\%) had paid to register their pregnancy at the health centre. Forty-two (79.2\%) perceived their health as having improved since they began to take ARV drugs. Ultimately, four (7.5\%) had their breastfeeding child having acquired HIV.

\subsection{Participant Satisfaction}

The instrument for participant satisfaction with the PMTCT programme at the hospital yielded a Cronbach's alpha of 0.92 . The mean satisfaction score was bimodal with a median of $28(\mathrm{IQR}=8)$. The 33.3 percentile was 25 and the 66.7 percentile was at a total score of 30 . Thus, scores below 25 implied poor satisfaction and a score of 30 implied complete satisfaction. Values in between reflected 
Table 1. Demographic characteristics $(n=53)$.

\begin{tabular}{|c|c|c|}
\hline Variable & Frequency & Percentage \\
\hline \multicolumn{3}{|l|}{ Level of education } \\
\hline Primary & 11 & 20.8 \\
\hline Secondary & 41 & 77.4 \\
\hline Tertiary & 1 & 1.9 \\
\hline \multicolumn{3}{|l|}{ Place of residence } \\
\hline Urban & 7 & 13.2 \\
\hline Rural & 46 & 86.8 \\
\hline \multicolumn{3}{|l|}{ Employment } \\
\hline Formally employed & 8 & 15.1 \\
\hline Self-employed & 15 & 28.3 \\
\hline Unemployed & 30 & 56.6 \\
\hline \multicolumn{3}{|l|}{ Monthly income } \\
\hline$\$ 0-\$ 250$ & 46 & 86.8 \\
\hline$\$ 251-\$ 600$ & 6 & 11.3 \\
\hline Above $\$ 600$ & 1 & 1.9 \\
\hline \multicolumn{3}{|l|}{ Religion } \\
\hline Christianity & 48 & 90.6 \\
\hline Traditionalist & 2 & 3.8 \\
\hline Moslem & 3 & 5.7 \\
\hline \multicolumn{3}{|l|}{ Duration on ART } \\
\hline Less than 3 months & 7 & 13.2 \\
\hline $3-12$ months & 10 & 18.9 \\
\hline 1 to 3 years & 20 & 37.7 \\
\hline More than 3 years & 16 & 30.2 \\
\hline \multicolumn{3}{|l|}{ Stage in PMTCT } \\
\hline Pregnant & 30 & 56.6 \\
\hline Breastfeeding & 23 & 43.4 \\
\hline \multicolumn{3}{|l|}{ Family Planning method } \\
\hline None & 2 & 3.8 \\
\hline Male condom & 19 & 35.8 \\
\hline Female condom & 3 & 5.7 \\
\hline Jadelle $^{\oplus}$ & 3 & 5.7 \\
\hline Depo Provera ${ }^{\circledR}$ & 10 & 18.8 \\
\hline POP & 13 & 24.5 \\
\hline $\mathrm{COC}$ & 3 & 5.7 \\
\hline \multicolumn{3}{|c|}{ Disclosed to husband or partner } \\
\hline Yes & 53 & 100.0 \\
\hline Total & 53 & 100 \\
\hline
\end{tabular}


Table 2. PMTCT centre visit information $(\mathrm{n}=53)$.

\begin{tabular}{|c|c|c|}
\hline Variable & Frequency & Percentage \\
\hline \multicolumn{3}{|c|}{ Is this your usual source of health care } \\
\hline No & 6 & 11.3 \\
\hline Yes & 47 & 88.7 \\
\hline \multicolumn{3}{|l|}{ Travel time to hospital } \\
\hline Less than 1 hour & 27 & 50.9 \\
\hline $1-3$ hours & 19 & 35.8 \\
\hline More than 3 hours & 7 & 13.2 \\
\hline \multicolumn{3}{|l|}{ Duration of exposure to Hospital } \\
\hline Less than 6 months & 6 & 11.3 \\
\hline $6-12$ months & 11 & 20.8 \\
\hline $1-3$ years & 16 & 30.2 \\
\hline More than 3 years & 20 & 37.7 \\
\hline \multicolumn{3}{|l|}{ Hospital visits in past 2 months } \\
\hline None & 28 & 52.8 \\
\hline One or two & 9 & 17.0 \\
\hline More than 2 & 16 & 30.2 \\
\hline \multicolumn{3}{|l|}{ Hospital visits in the past year } \\
\hline None & 23 & 43.4 \\
\hline One or two & 13 & 24.5 \\
\hline More than 2 & 17 & 32.1 \\
\hline \multicolumn{3}{|c|}{ Hospital being planned centre of delivery } \\
\hline Yes & 39 & 73.6 \\
\hline No & 14 & 26.4 \\
\hline \multicolumn{3}{|l|}{ Type of visit } \\
\hline Scheduled & 42 & 79.2 \\
\hline Unscheduled & 11 & 20.8 \\
\hline \multicolumn{3}{|l|}{ Missed a scheduled visit } \\
\hline Yes & 13 & 24.5 \\
\hline No & 33 & 62.3 \\
\hline \multicolumn{3}{|l|}{ Transport cost per visit } \\
\hline No direct monetary cost & 8 & 15.9 \\
\hline Less than $\$ 10$ & 42 & 79.2 \\
\hline$\$ 11-\$ 20$ & 3 & 5.7 \\
\hline \multicolumn{3}{|l|}{ Membership to a support group } \\
\hline Yes & 13 & 24.5 \\
\hline No & 36 & 66.0 \\
\hline Do not know & 4 & 7.5 \\
\hline \multicolumn{3}{|l|}{ Coming for PMTCT with partner } \\
\hline Yes & 22 & 41.5 \\
\hline No & 31 & 58.5 \\
\hline
\end{tabular}


Table 3. PMTCT experience.

\begin{tabular}{|c|c|c|}
\hline Variable & Frequency & Percentage \\
\hline \multicolumn{3}{|l|}{ Receiving peer support } \\
\hline Yes & 14 & 26.4 \\
\hline No & 39 & 73.6 \\
\hline \multicolumn{3}{|l|}{ Receiving community health worker support } \\
\hline Yes & 18 & 34.0 \\
\hline No & 35 & 66.0 \\
\hline \multicolumn{3}{|l|}{ Having had a cell phone reminder for PMTCT services } \\
\hline Yes & 15 & 28.3 \\
\hline No & 38 & 71.7 \\
\hline \multicolumn{3}{|l|}{ Cash motivation to come for visits } \\
\hline Yes & 5 & 9.4 \\
\hline No & 48 & 90.6 \\
\hline \multicolumn{3}{|l|}{ Referral for: } \\
\hline Blood tests & 2 & 3.8 \\
\hline X-ray & 8 & 15.1 \\
\hline Antiretroviral drugs & 0 & 0.0 \\
\hline Cotrimoxazole & 4 & 7.5 \\
\hline Hospital admission & 4 & 7.5 \\
\hline Outpatient treatment & 1 & 1.9 \\
\hline \multicolumn{3}{|l|}{ Sex of health care worker } \\
\hline Male & 1 & 1.9 \\
\hline Female & 52 & 98.1 \\
\hline \multicolumn{3}{|l|}{ Know health worker by name } \\
\hline Yes & 26 & 49.1 \\
\hline No & 27 & 50.9 \\
\hline \multicolumn{3}{|l|}{ Services paid for } \\
\hline Booking & 46 & 86.8 \\
\hline Consultation & 1 & 1.9 \\
\hline Supplies or equipment & 5 & 9.4 \\
\hline Medication & 2 & 3.8 \\
\hline Laboratory tests & 3 & 5.7 \\
\hline \multicolumn{3}{|l|}{ Present health } \\
\hline Excellent & 26 & 49.1 \\
\hline Good & 16 & 30.2 \\
\hline Average & 10 & 18.9 \\
\hline Poor & 1 & 1.9 \\
\hline \multicolumn{3}{|l|}{ Progress in PMTCT } \\
\hline Improved & 42 & 79.2 \\
\hline Still the same & 8 & 15.1 \\
\hline Worsened & 3 & 5.7 \\
\hline Satisfied with family support in PMTCT & 48 & 90.6 \\
\hline Satisfied community support in PMTCT & 37 & 69.8 \\
\hline \multicolumn{3}{|l|}{ Current HIV status of child } \\
\hline Positive & 4 & 7.5 \\
\hline Negative & 30 & 56.6 \\
\hline Unknown & 19 & 35.9 \\
\hline
\end{tabular}


optimal satisfaction. Nineteen (35.8\%) had complete satisfaction with PMTCT services at the hospital, Figure 1.

Multiple linear regression yielded two statistically significant predictors of missing a visit, namely; satisfaction with family support $(\beta=-0.73, p=0.029)$ and level of satisfaction $(\beta=-0.00076 ; p=0.04)$. On the other hand, there was an inverse correlation between the current visit number and the number of missed days $(\beta=-2.99, p=0.04)$. Other predictors of missed PMTCT visits such as income, transport cost to health facility, CD4 count, peer support and community health worker support were not statistically significant.

\section{Discussion}

Findings from this study showed that $24.5 \%$ of the women missed a scheduled visit. Satisfaction with the PMTCT programme at the health centre and family support were associated with not missing a PMTCT visit. Not surprisingly, participants who had just been commenced on PMTCT, that is, with few PMTCT visits were more likely to miss a scheduled visit by more days.

In this study $24.5 \%$ participants missed the scheduled PMTCT visit. This was a lower figure than in a national survey whereby $43 \%$ were lost to follow up by the time of the third drug pick up [5]. However, missing a single PMTCT visit can neither be directly inferred to retention in PMTCT nor to attrition. In this study, peer support and community health worker support were not statistically significant predictors of missed visits. This is not surprising since most community interventions have not been proven to improve retention in PMTCT [13]. For instance, use of community health workers, counselling in the community and HIV disclosure [14] [15]. This may be possible because the interventions tended to give women in PMTCT a passive role in the programme. In this study, participants had not received support: 66\% were not members of a PMTCT support group, $73.6 \%$ had received no peer support, $90.6 \%$ had received no cash

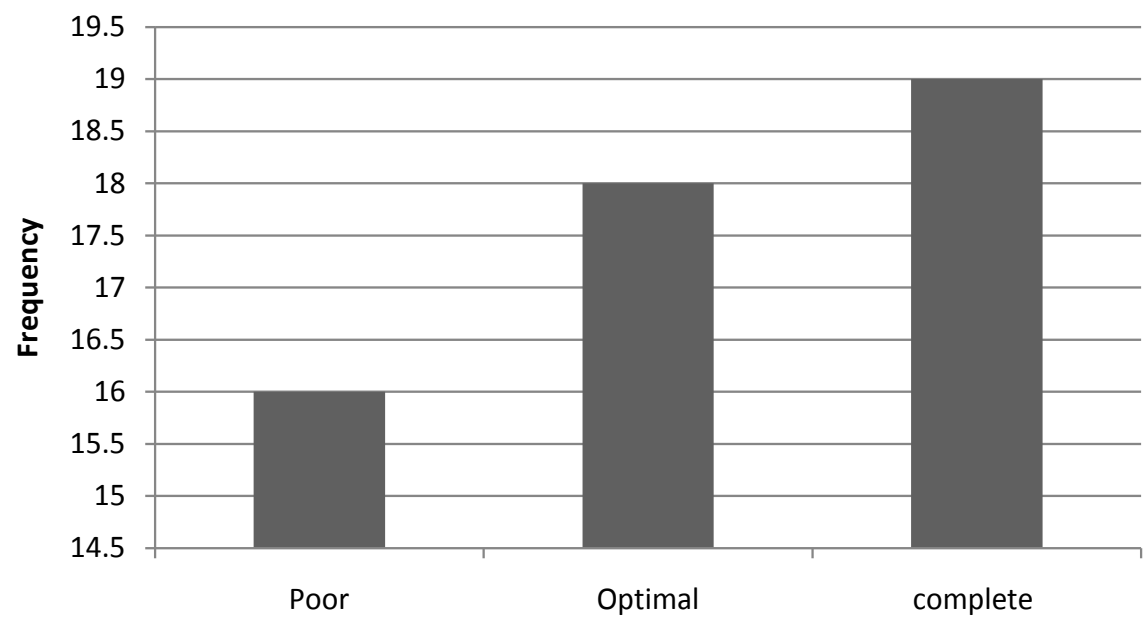

Level of satisfaction with PMTCT services

Figure 1. Level of satisfaction with PMTCT services at the hospital. 
motivation, and $71.7 \%$ had no cell phone reminders. This may imply that coming for scheduled PMTCT visits is much of individual effort. Surprisingly, a study in South Africa found that by six weeks after delivery, $24 \%$ women had missed a PMTCT visit [16].

In this study, 35.8\% participants had complete satisfaction with PMTCT services. This was a low figure compared to a study in Dar es Salaam where $61 \%$ had very good satisfaction. In the Dar es Salaam study, predictors of dissatisfaction included long waiting times, poor comprehension of patient needs and poor interpersonal skills of health workers [17]. In the current study, consultation rooms were quite small and did not offer privacy as other women could overhear conversations between clinicians and patients. Moreover, the consultation began in an open tent, which, however, provided a conducive opportunity for peer interaction. This may imply that women in PMTCT prefer privacy and are somewhat selective on whom to interact with. This may also be supported by the fact that peer support was not a statistically significant predictor of missed visits.

Statistically significant predictors for not missing visits were participants' satisfaction with family support and satisfaction with PMTCT services at the hospital. In this study, $90.6 \%$ were satisfied with family support and $69.8 \%$ were satisfied with community support. The findings contrast with a Haitian study whereby socio-demographics were not predictors of retention in care [18]. A Zimbabwean study also did not find a statistically significant improvement in retention of women after engaging facility-based peer support groups [19]. In the current study, participants may have wanted family acceptance to come for scheduled visits. PMTCT benefits the family, in part, by reducing vertical transmission of HIV to the child. Elsewhere, satisfaction with facility PMTCT services has been shown to improve retention. The coefficient of determination of $11 \%$ in the current study implies that there are other predictors responsible for $89 \%$ of variance in missed visits.

However, the statistical power in the current study may have been compromised by the small sample size. The study was also done in a single month, which might have produced a selection bias.

\section{Conclusion}

Family support and satisfaction with the handling of the PMTCT program may reduce the likelihood of missed PMTCT visits. Women tend to have more missed days in the later days of the PMTCT cascade. A more comprehensive PMTCT site assessment is required. The site assessment may include site retention strategies and the presence of a sustainable PMTCT model capable of retaining women in PMTCT. Hence, reducing the frequency of missed visits may facilitate understanding of health care and community predictors of missed visits. Lastly, a qualitative study to explore the reasons why women miss scheduled PMTCT later after enrollment into the PMTCT programme, may be done to explain patient fatigue along the PMTCT cascade. 


\section{Acknowledgements}

The authors would like to acknowledge the Provincial Medical Director, Mashonaland East Province and the District Medical Officer, Goromonzi for their support in data collection. This work is supported by the Norwegian Agency for Capacity Development (NORHED).

\section{References}

[1] Ministry of Health and Child Care (2014) Elimination of Mother to Child Transmission of HIV and Keeping Mother Alive: eMTCT Stock Taking Report 2013. Ministry of Health and Child Care, Harare, Zimbabwe.

[2] World Health Organization (2015) WHO Validates Elimination of Mother-to-Child Transmission of HIV and Syphilis in Cuba. Saudi Medical Journal, 36, 1018-1019.

[3] World Health Organization (2016) WHO Validates Elimination of Mother-to-Child Transmission of HIV and Syphilis in Armenia, Belarus and the Republic of Moldova. WHO, Copenhagen.

[4] World Health Organization (2014) Global Guidance on Criteria and Processes for Validation: Elimination of Mother-to-Child Transmission [EMTCT] of HIV and Syphilis. WHO Press, Geneva.

[5] Ministry of Health and Child Care (2013) Survey on Retention of Mothers and Infants in the PMTCT Program and Aherence to ARV Prophylaxis/ART in Zimbabwe. National AIDS and Tuberculosis Unit, Harare, Zimbabwe.

[6] Joint United Nations Programme on HIV/AIDS [UNAIDS] (2014) 90-90-90 An Ambitious Treatment Target to Help End the AIDS Epidemic. UNAIDS, Geneva.

[7] WHO (2016) Global Report on Early Warning Indicators of HIV Drug Resistance: Technical Report, July 2016. World Health Organization, Geneva, Switzerland.

[8] WHO (2017) Global Action Plan on HIV Drug Resistance 2017-2021. World Health Organization, Geneva.

[9] Geldsetzer, P., Yapa, H.M., Vaikath, M., Ogbuoji, O., Fox, M.P., Essajee, S.M., et al. (2016) A Systematic Review of Interventions to Improve Postpartum Retention of Women in PMTCT and ART Care. Journal of the International AIDS Society, 19, 20679. https://doi.org/10.7448/IAS.19.1.20679

[10] Ambia, J. and Mandala, J. (2016) A Systematic Review of Interventions to Improve Prevention of Mother-to-Child HIV Transmission Service Delivery and Promote Retention. Journal of the International AIDS Society, 19, 20309. https://doi.org/10.7448/IAS.19.1.20309

[11] Wesevich, A., Mtande, T., Saidi, F., Cromwell, E., Tweya, H., Hosseinipour, M.C., et al. (2017) Role of Male Partner Involvement in ART Retention and Adherence in Malawi's Option B+ Program. AIDS Care, 29, 1417-1425. https://doi.org/10.1080/09540121.2017.1308464

[12] Divine, G., Norton, H.J., Hunt, R. and Dienemann, J. (2013) A Review of Analysis and Sample Size Calculation Considerations for Wilcoxon Tests. Anesthesia \& Analgesia, 117, 699-710. https://doi.org/10.1213/ANE.0b013e31827f53d7

[13] Oyeledun, B., Phillips, A., Oronsaye, F., Alo, O.D., Shaffer, N., Osibo, B., et al. (2017) The Effect of a Continuous Quality Improvement Intervention on Retention-in-Care at 6 Months Postpartum in a PMTCT Program in Northern Nigeria: Results of a Cluster Randomized Controlled Study. JAIDS Journal of Acquired Immune Deficiency Syndromes, 75, S156-S164. 
https://doi.org/10.1097/QAI.0000000000001363

[14] Nance, N., Pendo, P., Masanja, J., Ngilangwa, D.P., Webb, K., Noronha, R., et al. (2017) Short-Term Effectiveness of a Community Health Worker Intervention for HIV-Infected Pregnant Women in Tanzania to Improve Treatment Adherence and Retention in Care: A Cluster-Randomized Trial. PLOS ONE, 12, e0181919. https://doi.org/10.1371/journal.pone.0181919

[15] Sarko, K.A., Blevins, M., Ahonkhai, A.A., Audet, C.M., Moon, T.D., Gebi, U.I., et al. (2017) HIV Status Disclosure, Facility-Based Delivery and Postpartum Retention of Mothers in a Prevention Clinical Trial in Rural Nigeria. International Health, 9, 243-251. https://doi.org/10.1093/inthealth/ihx023

[16] Phillips, T., Thebus, E., Bekker, L.G., Mcintyre, J., Abrams, E.J. and Myer, L. (2014) Disengagement of HIV-Positive Pregnant and Postpartum Women from Antiretroviral Therapy Services: A Cohort Study. Journal of the International AIDS Society, 17, 19242. https://doi.org/10.7448/IAS.17.1.19242

[17] Naburi, H., Mujinja, P., Kilewo, C., Barnighausen, T., Orsini, N., Manji, K., et al. (2016) Predictors of Patient Dissatisfaction with Services for Prevention of Mother-to-Child Transmission of HIV in Dares Salaam, Tanzania. PLoS ONE, 11, e0165121. https://doi.org/10.1371/journal.pone.0165121

[18] Dionne-Odom, J., Massaro, C., Jogerst, K.M., Li, Z., Deschamps, M.M., Destine, C.J., et al. (2016) Retention in Care among HIV-Infected Pregnant Women in Haiti with PMTCT Option B. AIDS Research and Treatment, 2016, Article ID: 6284290. https://doi.org/10.1155/2016/6284290

[19] Foster, G., Orne-Gliemann, J., Font, H., Kangwende, A., Magezi, V., Sengai, T., et al. (2017) Impact of Facility-Based Mother Support Groups on Retention in Care and PMTCT Outcomes in Rural Zimbabwe: The EPAZ Cluster-Randomized Controlled Trial. JAIDS Journal of Acquired Immune Deficiency Syndromes, 75, S207-S215. https://doi.org/10.1097/QAI.0000000000001360 